\title{
New Downy Mildew Disease Caused by Hyaloperonospora brassicae on Pak choi (Brassica rapa) in Korea
}

\author{
*Corresponding author \\ Tel: +82-63-469-4582 \\ Fax: +82-63-469-7421 \\ E-mail: yjchoi@kunsan.ac.kr \\ ORCID \\ https://orcid.org/0000-0002-0909-4723
}

Received June 14, 2019

Accepted June 18, 2019

\author{
Hyun Ju Lee ${ }^{1}$, Jae Sung Lee ${ }^{2}$, and Young-Joon Choi ${ }^{2 *}$ \\ 'Gyeonggido Agricultural Research \& Extension Services, Hwaseong 18388, Korea \\ ${ }^{2}$ Department of Biology, Kunsan National University, Gunsan 54150, Korea
}

\begin{abstract}
Pak choi (or a Bok choy; Brassica rapa subsp. chinensis) is a popular brassicaceous vegetable worldwide. In January 2019, a downy mildew symptom on pak choi was found at a farm located in Yongin, Korea. Based on morphological characteristics and molecular phylogenetic inference, the pathogenic oomycete was identified as Hyaloperonospora brassicae. To our knowledge, this is the first report of downy mildew disease occurring on pak choi in Korea. Considering the increasing demand for this crop, this pathogen would be a potentially new threat to the cultivation of pak choi in Korea.
\end{abstract}

Keywords: Brassica, downy mildew, Oomycota, pak choi, phylogeny
Downy mildew disease is caused by members of the family Peronosporaceae, the largest obligate pathogenic group of the phylum Oomycota. They infect a high number of flowering plants, ranging mono- to dicotyledonous plants (Thines and Choi, 2016). Among twenty genera of this family, Hyaloperonospora consists of approximately 50 species, most of which were specialized to a particular host genus or species of the Brassicaceae and allied families (Choi et al., 2011, 2018; Göker et al., 2004, 2009; Lee et al., 2017; Voglmayr and Göker, 2011; Voglmayr et al., 2014). An infamous species Hyaloperonospora brassicae causes destructive damages on Brassica, Raphanus, and Sinapis species, including many economically relevant crops such as broccoli, cabbage, radish, rape, tatsoi, and wasabi (Channon, 1981; Dickinson and Greenhalgh, 1977; Thines and Choi, 2016; Yerkes and Shaw, 1959).

Pak choi (or Bok choy; Brassica rapa subsp. chinensis) has been cultivated as an economically important vegetable since the fifth century in Asia (Fahey, 2003). There has been an increase in the production of this crop in Korea, because it

Research in Plant Disease

pISSN 1598-2262, elSSN 2233-9191

www.online-rpd.org is tasty, versatile, and nutritious but also can be easily grown. In January 2019, symptoms of downy mildew disease were found on pak choi at a plastic house located in Yongin-si in Korea (37 $21^{\prime} 15.0 » N$ N $127^{\circ} 14^{\prime} 18.3 »$ E) (Fig. 1A). A representative herbarium specimen was preserved in the Kunsan National University Herbarium (KSNUH378). To identify the causal pathogen, morphological and molecular phylogenetic analyses were performed.

For morphological identification, conidiophores and conidia protruding from the stomata of the infected leaves were placed on a drop of distilled water on a slide glass and covered with a cover slip. The preparate was examined under a DIC-light microscope BX53F (Olympus, Tokyo, Japan) and photographed with a DigiRetina 16M digital camera (Tucsen, Fuzhou, China). Initial downy mildew symptoms on the pak choi appeared as yellowish to green-yellowish spots on the upper surface of leaves (Fig. 1E), while conidiophores and conidia occurred densely on the corresponding lower surface (Fig. 1F). Disease incidence ranged from 20 to $30 \%$. Conidiophores $(n=50)$ were hyaline, 200 450 $\mu \mathrm{m}$ in length, monopodially branched in 3-5 orders, while trunks were straight to slightly curved, 100 300 $\mu \mathrm{m}$ in length, with slightly swollen basal end of 8 15 $\mu$ m wide (Fig. 1G). Ulti- 


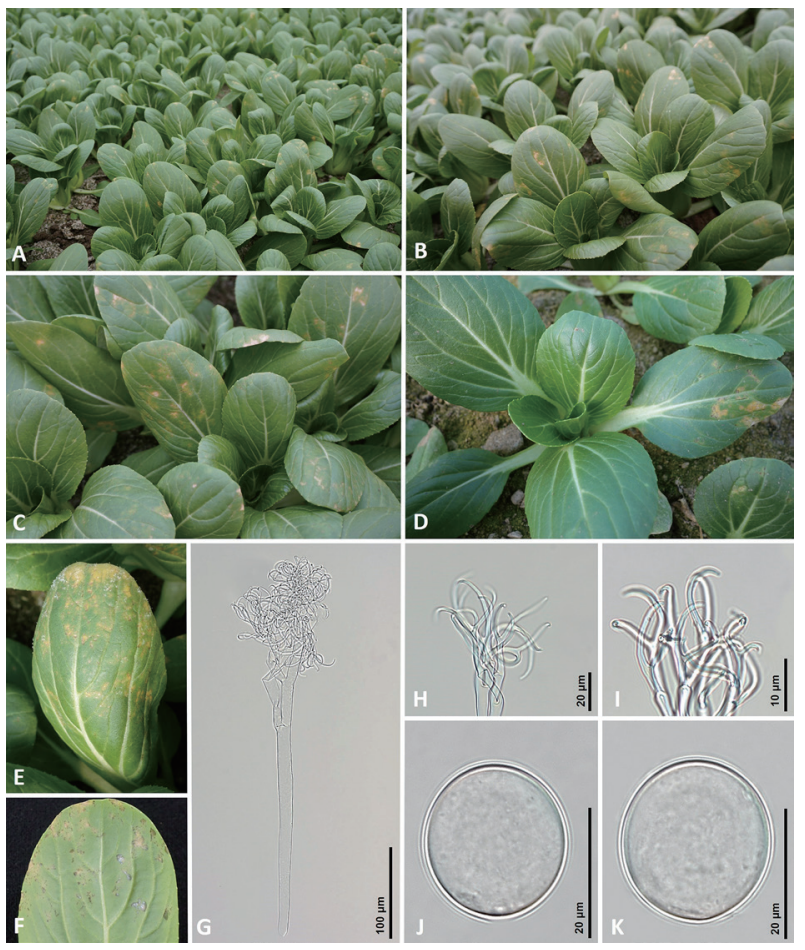

Fig. 1. Downy mildew disease caused by Hyaloperonospora brassicae on pak choi (Brassica rapa subsp. chinensis). (A, B) Downy mildew occurrence in a plastic farm. (C, D) Initial symptom with yellowish leaf spots. (E) Vein-limited spots on the upper leaf surface. (F) Whitish oomycete matrix on the lower surface. (G) Conidiophore. $(\mathrm{H}, \mathrm{I})$ Ultimate branchlets. (J, K) Conidia. Source: KSNUH378

mate branchlets ( $\mathrm{n}=50$ ) were mostly in pairs, curved sigmoid, 10 30 $\mu \mathrm{m}$ long, and displayed obtuse subtruncate tips (Fig. $1 \mathrm{H}-\mathrm{I})$. Conidia $(\mathrm{n}=100)$ were broadly subglobose, whitish, and measured 21.0 28.5 × 20.0 25.5 $\mu \mathrm{m}$ (av. $25.2 \times 22.86$ $\mu \mathrm{m}$ ) with a ratio of length to width of 1.01 1.21 (av. 1.10) (Fig. 1J-K). All morphological characteristics closely matched those of H. brassicae known on Brassica species (Choi et al., 2012; Gäumann, 1923; Hong et al., 2008).

To confirm the morphological identification, two barcode markers of oomycetes, the internal transcribed spacer (ITS) rDNA and cytochrome oxidase II (cox2) mtDNA were compared with the sequences of other Hyaloperonospora species. DNA was extracted from an infected leaf of KSNUH378, using the MagListo 5M Plant Genomic DNA Extraction Kit (Bioneer, Daejeon, Korea). PCR amplifications of ITS rDNA and cox2 mtDNA were performed as using procedures outlined by Choi et al. (2015). The amplicons were purified using an AccuPrep PCR Purification Kit (Bioneer, Daejeon, Korea) and sequenced by a DNA sequencing service (Macrogen, Seoul, Korea), with the same primers used for amplification. The re-
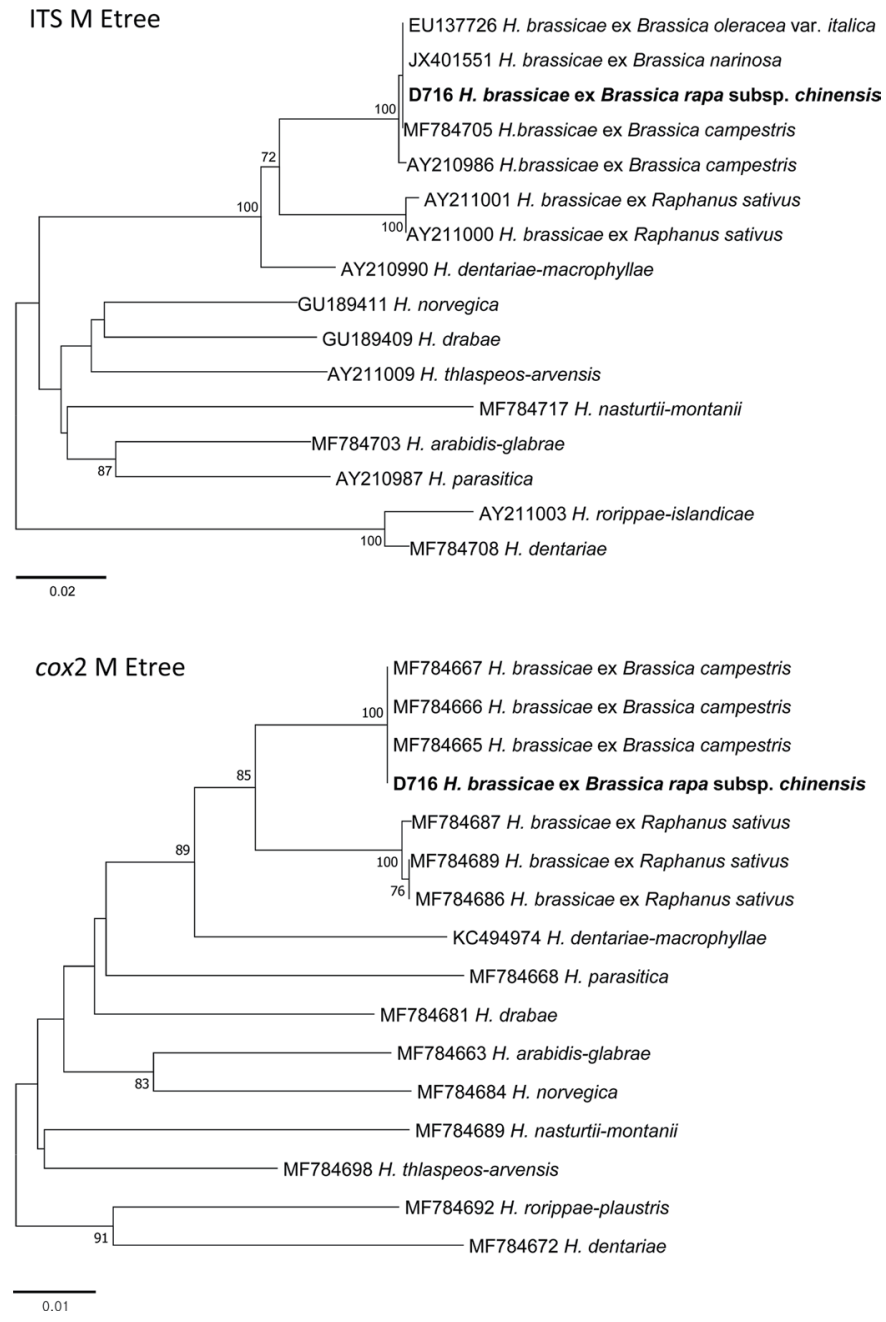

Fig. 2. Minimum evolution trees based on the internal transcribed spacer rDNA and cytochrome oxidase II mtDNA sequences. Bootstrapping values higher than $70 \%$ are given above the branches. Downy mildew pathogen of pak choi (Brassica rapa subsp. chinensis) is shown in bold. The scale bar equals the number of nucleotide substitutions per site.

sulting sequences were edited with the DNASTAR software package version 5.05 (DNASTAR, Madison, WI, USA) and deposited in GenBank (accession nos. MN065156 for ITS rDNA, MN072364 for cox2 mtDNA). In addition to the reference sequences of Hyaloperonospora species available in $\mathrm{NCBI}$ GenBank, they were aligned by MAFFT 7 (Katoh and Standley, 2013). In order to infer their phylogenetic relationship, minimum evolution (ME) analysis was performed in MEGA7 (Kumar et al., 2016) with the default settings, except for replacement with the Tamura-Nei model. Robustness of each tree was evaluated with 1,000 bootstrap replicates. BLASTn search revealed that the ITS sequence of the downy mildew pathogen of the pak choi is identical with those of Hyalo- 
peronospora brassica on Brassica spp. (EU137726, JX401551, MF784705) in NCBI GenBank. Similarly, the cox2 sequence corresponds with H. brassicae on B. campestris (MF784667, MF784665, MF784666). In the phylogenetic trees for ITS rDNA (Fig. 2A) and cox2 mtDNA (Fig. 2B), the present pathogen was grouped with the sequences of $H$. brassicae of Brassica spp. with a high supporting value of $100 \%$, proving its identity as $H$. brassicae.

Over the last 100 years, $H$. brassicae (formerly, Peronospora parasitica) was one of the most destructive pathogens in cultivations of Brassica plants in the world (Channon, 1981; Kluczewski and Lucas, 1983; Monot et al., 2010; Sherriff and Lucas, 1990). In Korea, this pathogen has been attributed the downy mildew diseases occurring on brown mustard, Chinese cabbage, cabbage, broccoli, and tatsoi (Choi et al., 2012; Hong et al., 2008; Shin and Choi, 2006; The Korean Society of Plant Pathology, 2004). On pak choi, the disease has been previously recorded in China, Fiji, Malaysia, Papua New Guinea (Farr and Rossman, 2019), and Japan (Chu, 1935). This is the first record of $\mathrm{H}$. brassicae on pak choi in Korea. Considering the increasing demand for this crop, this disease may cause a serious risk to the cultivation of pak choi.

\section{Conflicts of Interest}

No potential conflict of interest relevant to this article was reported.

\section{Acknowledgements}

This work was supported by the National Research Foundation of Korea (NRF) grant funded by the Korea government (MSIT) (2019R1C1C1002791), Republic of Korea.

\section{References}

Channon, A. G. 1981. Downy mildew of brassicas. In: The Downy Mildews, ed. by D. M. Spencer, pp. 321-339. Academic Press, London, UK.

Choi, Y. J., Shin, H. D. and Voglmayr, H. 2011. Reclassification of two Peronospora species parasitic on Draba in Hyaloperonospora based on morphological molecular and phylogenetic data. Mycopathologia 171: 151-159.

Choi, Y. J., Kim, J. Y., Park, J. H. and Shin, H. D. 2012. First report of tatsoi downy mildew caused by Hyaloperonospora brassicae in Korea. Plant Dis. 96: 1703.
Choi, Y. J., Beakes, G., Glockling, S., Kruse, J., Nam, B., Nigrelli, L. et al. 2015. Towards a universal barcode of oomycetes - a comparison of the cox 1 and cox 2 loci. Mol. Ecol. Resour. 15: 1275-1288.

Choi, Y.-J., Kruse, J. and Thines, M. 2018. Hyaloperonospora erucae sp. nov. (Peronosporaceae; Oomycota), the downy mildew pathogen of arugula (Eruca sativa). Eur. J. Plant Pathol. 151: 549-555.

Chu, H. 1935. Notes on the penetration phenomena and haustorium formation in Peronospora brassicae Gäum. Jpn. J. Phytopathol. 5: 150-157 (in Japanese).

Dickinson, C. H. and Greenhalgh, J. R. 1977. Host range and taxonomy of Peronospora on Crucifers. Trans. Br. Mycol. Soc. 69: 111116.

Fahey, J. 2003. Brassicas. In: Encyclopedia of food sciences and nutrition, eds. by B. Caballero, L. C. Trugo and P. M. Finglas, pp. 606615. Academic Press, London, UK.

Farr, D. F. and Rossman, A. Y. 2019. Fungal databases, systematic mycology and microbiology laboratory. URL https://nt.ars-grin. gov/fungaldatabases/ [11 June 2019].

Gäumann, E. A. 1923. Contributions toward a monograph of the genus Peronospora corda. Beitrage zur Kryptogamenflora der Schweiz 5: 1-360 (in German).

Göker, M., Riethmüller, A., Voglmayr, H., Weiss, M. and Oberwinkler, F. 2004. Phylogeny of Hyaloperonospora based on nuclear ribosomal internal transcribed spacer sequences. Mycol. Prog. 3: 8394.

Göker, M., Voglmayr, H., Blázquez, G. G. and Oberwinkler, F. 2009. Species delimitation in downy mildews: the case of Hyaloperonospora in the light of nuclear ribosomal ITS and LSU sequences. Mycol. Res. 113: 308-325.

Hong, S. Y., Jee, H. J., Choi, Y. J. and Shin, H. D. 2008. First confirmed report of downy mildew caused by Hyaloperonospora parasitica on broccoli in Korea. Plant Pathol. 57: 777.

Katoh, K. and Standley, D. M. 2013. MAFFT Multiple sequence alignment software version 7: Improvements in performance and usability. Mol. Biol. Evol. 30: 772-780.

Kluczewski, S. M. and Lucas, J. A. 1983. Host infection and oospore formation by Peronospora parasitica in agricultural and horticultural Brassica species. Trans. Br. Mycol. Soc. 81: 591-596.

Kumar, S., Stecher, G. and Tamura, K. 2016. MEGA7: molecular evolutionary genetics analysis version 7.0 for bigger datasets. Mol. Biol. Evol. 33: 1870-1874.

Lee, J. S., Lee, H. B., Shin, H.-D. and Choi, Y.-J. 2017. Diversity, phylogeny, and host-specialization of Hyaloperonospora species in Korea. Mycobiology 45: 139-149.

Monot, C., Penguilly, D. and Silué, D. 2010. First confirmed report of downy mildew caused by Hyaloperonospora parasitica on broccoli, cauliflower and Romanesco-type cauliflower heads in France. Plant Pathol. 59: 1165.

Sherriff, C. and Lucas, J. A. 1990. The host range of isolates of downy mildew, Peronospora parasitica, from Brassica crop species. Plant Pathol. 39: 77-91.

Shin, H. D. and Choi, Y. J. 2006. Peronosporaceae of Korea. National 
Institute of Agricultural Science and Technology, Suwon, Korea. 166 pp.

The Korean Society of Plant Pathology. 2004. List of plant diseases in Korea. 4th ed. The Korean Society of Plant Pathology, Suwon, Korea. 779 pp.

Thines, M. and Choi, Y. J. 2016. Evolution, diversity, and taxonomy of the Peronosporaceae, with focus on the genus Peronospora. Phytopathology 106: 6-18.

Voglmayr, H. and Göker, M. 2011. Morphology and phylogeny of
Hyaloperonospora erophilae and H. praecox sp. nov., two downy mildew species co-occurring on Draba verna sensu lato. Mycol. Prog. 10: 283-292.

Voglmayr, H., Choi, Y.-J. and Shin, H.-D. 2014. Multigene phylogeny, taxonomy and reclassification of Hyaloperonospora on Cardamine. Mycol. Prog. 13: 131-144.

Yerkes, W. D. and Shaw, C. G. 1959. Taxonomy of the Peronospora species on Cruciferae and Chenopodiaceae. Phytopathology 49: 499-507. 